\title{
LEVANTAMENTO DO LÉXICO LIGADO À RELIGIOSIDADE, TRABALHO E CULINÁRIA NA ZONA RURAL DE JEREMOABO
}

\author{
Thaise Leal de Souza ${ }^{1}$; Profa. Dra. Norma Lucia Fernandes de Almeida ${ }^{2}$ \\ 1. Bolsista IC-PIBIC/CNPq, Graduanda em Letras com espanhol, Universidade Estadual de Feira de \\ Santana, e-mail: thaisyleal@hotmail.com \\ 2. Orientadora, Departamento de Letras e Artes, Universidade Estadual de Feira de Santana, e-mail: \\ norma.uefs@gmail.com
}

PALAVRAS-CHAVE: léxico - zona rural - Jeremoabo

\section{INTRODUÇÃO}

Este trabalho tem como objetivo fazer a análise de palavras que recobrem a religiosidade, a culinária e o trabalho do homem sertanejo no município de Jeremoabo, o que nos direciona a pensar na relação intrínseca entre léxico e cultura. Além disso, esta investigação oportuniza a criação de um dicionário, que se faz muito pertinente em um trabalho como este, identificando palavras que agem de modo exclusivo e seus correspondentes significados, descrevendo situações distintas de usos da língua e possibilizando analisar as lexias de forma mais detalhada.

Jeremoabo é um município brasileiro situado no estado da Bahia. Sua população estimada em 2004 era de 33.103 habitantes. A porcentagem da população urbana, que era de apenas $12 \%$ em 1970, chegou a $40 \%$ do total do município em 1995. Atualmente, encontra-se com cerca de 44 mil habitantes. Contudo, Jeremoabo apresenta uma rica variação em seu léxico, constituindo, dessa forma, um terreno fértil para a análise e investigação linguística, atendendo, assim, a proposta desse projeto.

Contudo, nas próximas seções apresentaremos a descrição do material e metodologia aplicados neste estudo, seguida da apresentação dos resultados alcançados, e por fim, as considerações finais.

\section{MATERIAL E MÉTODOS OU METODOLOGIA (ou equivalente)}

O material a ser utilizado como corpus será constituído de entrevistas realizadas com moradores das comunidades de Casinhas, Pereiros e Lagoa do Inácio, distritos de Jeremoabo, pertencentes ao acervo do projeto de pesquisa A língua portuguesa falada no semiárido baiano, além de pesquisas em trabalhos relacionados ao assunto bem como informações retiradas de sites da internet.

Após a retirada dos dados, será realizada a análise do significado dado pelo informante, esse significado será confrontado com significados encontrados em dicionários contemporâneos e antigos no sentido de entender a manutenção ou não de significações mais antigas.

\section{RESULTADOS E/OU DISCUSSÃO (ou Análise e discussão dos resultados)}

Este trabalho objetiva discorrer sobre alguns processos da dinâmica léxica na alteração e formação de itens lexicais do meio sertanejo de Jeremoabo, e tem o objetivo de fazer uma reflexão acerca dos processos que motivam a aquisição, criação e alteração que ocorrem nas formas léxicas próprias do falar local dessa região. Para responder às novas necessidades ou transformações que encontra no seu ambiente linguístico, muitas vezes longe dos termos que preencheriam essas ideias, o sertanejo cria ou utiliza termos outros, como também dá novos significados a termos que já existem.

A amplitude lexical de uma língua confere a ela uma dinamicidade e também possibilita o registro da experiência cotidiana. Neste sentido, Biderman (1978), ao definir léxico, o considera o tesouro vocabular de uma determinada língua, que se compõe a partir de 
conceitos do mundo cultural e do mundo físico, do passado ao presente. Contudo, destacamos o fato de que as palavras mantêm uma intrínseca ligação entre si. O que nos importa é proceder a um levantamento de alguns campos léxicos, partindo das associativas relações de significados e de ideias. Compreender o significado e o uso de uma palavra em seu contexto de utilização e sua época é de grande relevância para o entendimento da cultura e da identidade dos atores sociais que utilizam tais palavras em seus processos de comunicação. Desta forma, analisar o léxico das atividades profissionais, religião e culinária de uma determinada comunidade ou grupo de pessoas possibilita compreender também a dinamicidade da cultura do grupo ou da comunidade.

Desta forma, vejamos a organização de algumas lexias em campos léxicos:

\section{POVOADO TAPERA}

\section{CULINÁRIA}

CANJICA - 1. Papa de milho ralado, cozido no leite; canjiquinha 2. Milho branco cozido e temperado com leite de coco; munguzá (FERREIRA, Aurélio Buarque de Holanda. Miniaurélio eletrônico, versão 5.12. $7^{\mathrm{a}}$ Ed., 2004, Editora Positivo) / 1. Grãos pilados de milho, arroz, trigo etc 2. Milho pilado, que se come cozido em água e sal ou com leite e açúcar (HOUAISS, Antonio. Dic. Michaelis UOL - Versão eletrônica, 1988, Rio de Janeiro) / Prato derivado do milho (Significado dado na comunidade).

Exemplo: Inf. mulher, 39 anos, analfabeta: "A canjica é... é a pamonha".

\section{RELIGIÃO}

BENDIZER - 1. Dizer bem de; louvar 2. Abençoar; benzer 3. Tornar próspero; proteger (FERREIRA, Aurélio Buarque de Holanda. Miniaurélio eletrônico, versão 5.12. $7^{\text {a }}$ Ed., 2004, Editora Positivo) / 1. Dizer bem de; louvar (HOUAISS, Antonio. Dic. Michaelis UOL - Versão eletrônica, 1988, Rio de Janeiro) / Como se fosse (Significado dado na comunidade).

Exemplo: Inf. homem, 21 anos, $2^{\mathrm{a}}$ série do ensino fundamental: "Probrema pa bendizer a que me criou".

\section{TRABALHO/LAVOURA}

TROVARIZAR - Não dicionarizada / Aplicação de veneno para exterminar pragas na lavoura (Significado dado na comunidade).

Exemplo: Inf. homem, 64 anos, analfabeto: "Atravéi de... de trovarizar, sabe"?

FUTUCAR - Não dicionarizada / Mexer com as coisas da roça (Significado dado na comunidade).

Exemplo: Inf. mulher, 65 anos, analfabeta: “Futucano minha roça”.

\section{CULINÁRIA}

\section{POVOADO DE CASINHAS}

CACO - 1. Fragmento de louça, vidro, etc 2. Objeto estragado, ou sem valor (FERREIRA, Aurélio Buarque de Holanda. Miniaurélio eletrônico, versão 5.12. $7^{\mathrm{a}}$ Ed., 2004, Editora Positivo) / Não consta (HOUAISS, Antonio. Dic Michaelis UOL - Versão eletrônica, 1988, Rio de Janeiro) / Tipo de vasilha (Significado dado na comunidade).

Exemplo: Inf. mulher, 23 anos, $4^{\mathrm{a}}$ série do ensino fundamental: “...no caco, na vazia instaladeira, sabe"?

VAZIA INSTALADEIRA - Não dicionarizada / Tipo de vasilha (Significado dado na comunidade).

Exemplo: Inf. mulher, 23 anos, $4^{\text {a }}$ série do ensino fundamental: "No caco, na vazia instaladeira, sabe"? 
TACHO - 1. Vaso de metal ou de barro, largo e pouco fundo, geralmente com asas 2. Piano desafinado (FERREIRA, Aurélio Buarque de Holanda. Miniaurélio eletrônico, versão 5.12. $7^{\text {a }}$ Ed., 2004, Editora Positivo) / 1. Vaso largo e pouco fundo de barro ou metal, geralmente com asas, próprio para usos culinários 2. Cozinheira, criada de convento 3. Piano velho e desafinado 4. Relógio ruim (HOUAISS, Antonio. Dic Michaelis UOL - Versão eletrônica, 1988, Rio de Janeiro) / Tipo de vaso (Significado dado na comunidade).

Exemplo: Inf. mulher, 62 anos, analfabeta: "Bota no tacho e agora aí passa de mão, bota o açúcar dento, mexe, aí dá o ponto, a gente tira”.

\section{$\underline{R E L I G I \tilde{A O}}$}

BENZER - 1. Fazer o sinal-da-cruz sobre (pessoa ou coisa), recitando certas fórmulas litúrgicas 2. Fazer benzeduras em 3. Abençoar (FERREIRA, Aurélio Buarque de Holanda. Miniaurélio eletrônico, versão 5.12. $7^{\mathrm{a}}$ Ed., 2004, Editora Positivo) / 1. Deitar a bênção a 2. Abençoar 3. Fazer uma cruz com a mão direita aberta da testa ao peito e do ombro esquerdo ao direito 4. Fazer benzeduras em (HOUAISS, Antonio. Dic. Michaelis UOL - Versão eletrônica, 1988, Rio de Janeiro) / Fazer o sinal da cruz (Significado dado na comunidade).

Exemplo: Inf. homem, 41 anos, analfabeto: "A pessoa tem que se chamar, se deitar e chamar por Deuso, se benzer, rezar".

\section{TRABALHO/LAVOURA}

RAPAR - 1. Desgastar, cortando em fragmentos ou lascas 2. Cortar rente o pelo de; raspar 3. Barbear-se (FERREIRA, Aurélio Buarque de Holanda. Miniaurélio eletrônico, versão 5.12. $7^{\text {a }}$ Ed., 2004, Editora Positivo) / 1. Cortar cerce 2. Cortar à navalha o pêlo de; escanhoar 3. Barbear-se, escanhoar-se 4. Roçar com os pés ou com as patas; escavar 5. Extorquir ardilosamente; furtar; rapinar; tirar com violência (HOUAISS, Antonio. Dic Michaelis UOL - Versão eletrônica, 1988, Rio de Janeiro) / Raspar (Significado dado na comunidade).

Exemplo: Inf. mulher, 55 anos, analfabeta: "Pegava a mandioca, rapava, cano acabar relava no ralo, esprimia, assim, no pano, quano acabar fazia beiju, quem num fazia beiju fazia assim, uma farinha assim, num caco".

DESTOPAR - Não dicionarizada / Limpar o solo (Significado dado na comunidade).

Exemplo: Inf. homem, 16 anos, 4a série do ensino fundamental: "Limpano terra, feijão, displan... \{destopano\} algum capim".

LABUTAR - 1. Trabalhar duro e com perseverança; lidar, laborar (FERREIRA, Aurélio Buarque de Holanda. Miniaurélio eletrônico, versão 5.12. $7^{\mathrm{a}}$ Ed., 2004, Editora Positivo) / 1. Trabalhar intensamente e com perseverança; laborar, lutar 2. Esforçar-se; lidar, pugnar 3. Funcionar com grande atividade (HOUAISS, Antonio. Dic Michaelis UOL - Versão eletrônica, 1988, Rio de Janeiro) / Trabalhar (Significado dado na comunidade).

Exemplo: Inf. mulher, 38 anos, alfabetizada: "Sei que ele labutou muito nessa fazenda coitado, até quande fícou véi e tá aí labutano, cego".

\section{CULINÁRIA}

\section{POVOADO LAGOA DO INÁCIO}

Nenhuma lexia encontrada.

\section{RELIGIÃO}

BENÇA - 1. Ação de benzer ou de abençoar 2. Graça divina (FERREIRA, Aurélio Buarque de Holanda. Miniaurélio eletrônico, versão 5.12. $7^{\mathrm{a}}$ Ed., 2004, Editora Positivo) / 1. Ação de benzer ou de abençoar 2. Favor divino; graça (HOUAISS, Antonio. Dic Michaelis UOL - Versão eletrônica, 1988, Rio de Janeiro) / Benção (Significado dado na comunidade). 
Exemplo: Inf. mulher, 45 anos, $3^{\text {a }}$ série do ensino fundamental: “...toda vez que ver a madrinha, toma a bença, tem educação, gosta da madrinha".

\section{$\underline{\text { TRABALHO/LAVOURA }}$}

AGUAR - 1. regar 2. Misturar água com (qualquer líquido) 3. Encher-se de água (FERREIRA, Aurélio Buarque de Holanda. Miniaurélio eletrônico, versão 5.12. $7^{\text {a }}$ Ed., 2004, Editora Positivo) / 1. Borrifar com água ou outro líquido; regar 2. Misturar água com qualquer outro líquido 3. Encher(-se) de água 4. Adoçar (as cores) misturando água 5. Ter aguamento (HOUAISS, Antonio. Dic Michaelis UOL - Versão eletrônica, 1988, Rio de Janeiro) / Regar (Significado dado na comunidade).

Exemplo: Inf. homem, 45 anos, $4^{\text {a }}$ série do ensino fundamental: "Aí cê já vai, cê vai aguano ele até a época da chuva chegar".

DEZOIAR - Não dicionarizada / Separar os "olhos" da planta para serem plantados pela segunda vez (Significado dado na comunidade).

Exemplo: Inf. homem, 45 anos, $4^{\mathrm{a}}$ série do ensino fundamental: "Agora cada foia sai um oi, cê vai dezoiar aquilo tudo pa depois sai a segunda..."

\section{CONSIDERAÇÕES FINAIS (ou Conclusão)}

À guisa de conclusão, este trabalho buscou contribuir para o entendimento da língua portuguesa como instrumento social de comunicação, dotado de uma unidade sistêmica que abrange várias normas de uso, com vistas a contemplar a unidade na diversidade, e promover a compreensão de que as diferenças não podem ser consideradas no seu aspecto sobretudo folclórico, mas sim como algo que define o ser humano: o sentimento de pertencer a determinada cultura.

Nessa perspectiva, o patrimônio cultural é passado às gerações posteriores através da linguagem, a língua é o que veicula por excelência a transmissão da cultura e o léxico de uma língua constitui um tesouro de signos linguísticos que, em forma de código semiótico, permite que isso ocorra. É conhecido que as unidades lexicais se manifestam como instrumento de representação de realidades não semelhantes. Logo, o léxico implica, de forma direta, uma experiência com o mundo real, ao manifestar a sua pluralidade e formar um sistema do qual os falantes lançam mão para realizar a sua seleção lexical, de acordo com as situações usuais da língua. Nessa lógica, acreditamos no enfoque de se observar os deslocamentos de sentido para fazer a linguagem vir à tona, essa força complexa e invisível que nos é atingível por um trabalho que só a língua em movimento tem capacidade de fornecer.

Em vista disso, os resultados que foram aqui encontrados, têm o objetivo de mostrar, acima de tudo, que a comunidade em questão apresenta em seu repertório linguístico, uma rica variedade em relação ao léxico, o qual vem sendo utilizado como forma criativa de inovação.

\section{REFERÊNCIAS}

BIDERMAN, M.T.C. TEORIA LINGUÍSTICA: linguística quantitativa e computacional. Rio de Janeiro: LTC, 1978.

FERREIRA, Aurélio Buarque de Holanda. MINIAURÉLIO ELETRÔNICO VERSÃo 5.12. $7^{\mathrm{a}}$ Ed., 2004, Editora Positivo.

HOUAISS, Antonio. DIC MICHAELIS UOL - VERSÃO ELETRÔNICA, 1988, Rio de Janeiro. 